\title{
Massive Cerebral Edema Associated with Meningioma
}

\author{
Venkita Jagadha and John H.N. Deck
}

\begin{abstract}
Cerebral edema is a well-known complication of malignant astrocytoma and metastatic brain tumour. Though far less frequent, the association of cerebral edema with meningioma is also recognized; this is unpredictable and sometimes out of proportion to tumour size. We describe three cases where the mass effect was due to severe edema, rather than the tumour itself and was responsible for a catastrophic clinical presentation. The mechanisms responsible for the development of severe edema with meningioma which have been previously proposed are reviewed. They include tumour size, location, histologic subtype, cellularity, mitotic activity, vascularity and the presence of excretory-secretory activity. None of these consistently correlate with cerebral edema. Our cases suggest that spontaneous hemorrhage into the tumour may be the common factor responsible for severe cerebral edema. It is stressed that though a decidedly rare complication, cerebral edema secondary to meningioma should be entertained in the differential diagnosis of acute neurologic deterioration of these patients.
\end{abstract}

RÉSUMÉ: Oedème cérébral important associé à un méningiome L'oedème cérébral est une complication bien connue de l'astrocytome malin et des tumeurs cérébrales d'origine métastatique. L'oedème cérébral associé à la présence d’un méningiome, quoique beaucoup moins fréquent, est aussi bien connu; cette association est imprévisible et parfois hors de proportion avec la taille de la tumeur. Nous décrivons trois cas chez qui la symptomatologie était due à un oedème sévère plutôt qu'à la tumeur elle-même et chez qui cet oedème était responsable d’un présentation clinique catastrophique. Nous revoyns les mécanismes responsables du développement d'un oedème cérébral sévère associé à un méningiome, tel que proposés antérieurement dans la littérature: la taille de la tumeur, sa localisation, le sous-type histologique, la cellularité, l'activité mitotique, la vascularité et la présence d'activité excrétoire-sécrétoire. Aucun de ces facteurs n'est en corrélation de façon constante avec l'oedème cérébral. L'hémorragie spontanée à l'intérieur de la tumeur est peut-être le facteur commun responsable de l'oedème cérébral sévère, tel que suggéré par l'étude de nos cas. Nous insistons sur le fait que, même si l'oedème cérébral secondaire à un méningiome est une complication rare, ce diagnostic doit être considéré dans le diagnostic différentiel lorsqu'il y a détérioration aiguë de l'état neurologique chez ces patients.

Can. J. Neurol. Sci. 1987; 14:55-58

Cerebral edema is often recognized as a complication of the later stages of growth of intracranial neoplasms. Metastatic brain tumour and malignant astrocytoma are often accompanied by severe cerebral edema. ' Though far less frequent, there is now increasing awareness of the association between cerebral edema and meningioma, ${ }^{2-7}$ the mechanism of which is poorly understood. It is also apparent from recent observations that on rare occasions, small meningiomas may present with unusually severe cerebral edema, out of proportion to the tumour size. In these instances, the severe edema, rather than the mass effects of the tumour itself, has been the cause of clinical symptoms. ${ }^{2,3}$ In the present report, we describe three patients who had a catastrophic presentation due to fatal cerebral edema with relatively small meningiomas. The previously proposed mechanisms of cerebral edema in this setting are reviewed. In all three of our patients, there was evidence of old intratumoural hemorrhage. We suggest that this may be the important common factor in cases of associated massive cerebral edema. It is stressed that even relatively asymptomatic meningiomas may have a precipitous apoplectiform onset.

\section{Case Reports}

Case 1

This 52 year old woman, with no significant prior neurologic history. underwent a cholecystectomy at a local hospital. The surgical procedure was apparently without complications; however, post-operatively the patient failed to recover consciousness and had to be maintained on a respirator. She expired within three days of surgery. The clinical impression was a brainstem hemorrhage.

A medico-legal autopsy was performed. Examination of various organ systems showed minimal old fibrous scarring of the left ventricular myocardium, minimal coronary atherosclerosis, acute laryngitis and tracheitis and patchy bronchopneumonia. There was no evidence

From the Division of Neuropathology. Department of Pathology. University of Toronto and Toronto General Hospital

Received May 6, 1986. Accepted in final form September 15, 1986.

Reprint requests to: John H.N. Deck, M.D.. Department of Pathology. Toronto General Hospital. 200 Elizabeth Street. Toronto. Ontario. Canada M5G 2C4 


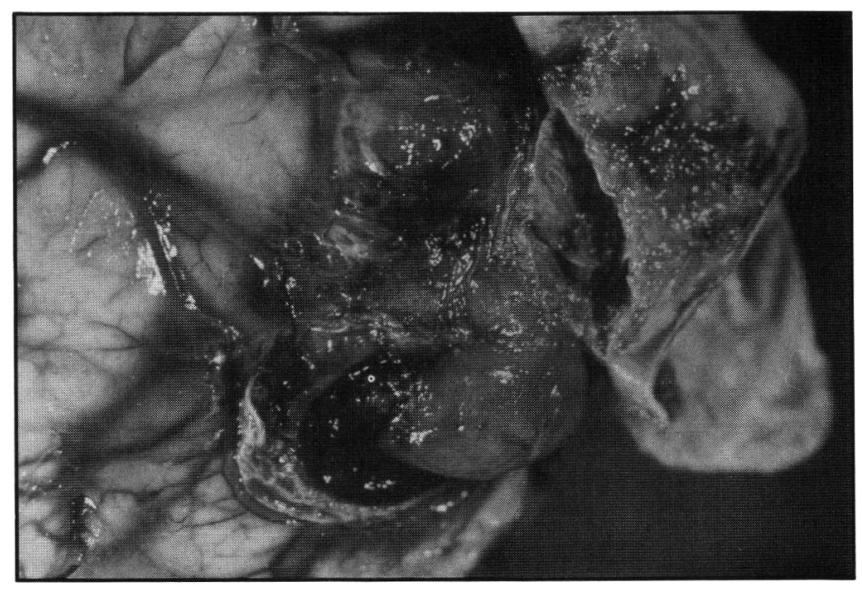

Figure I - Case I - Small meningioma embedded in left frontal pole with attached dura mater on the right. Leptomeninges around the tumour are fibrotic and firmly attach the tumour to the brain.

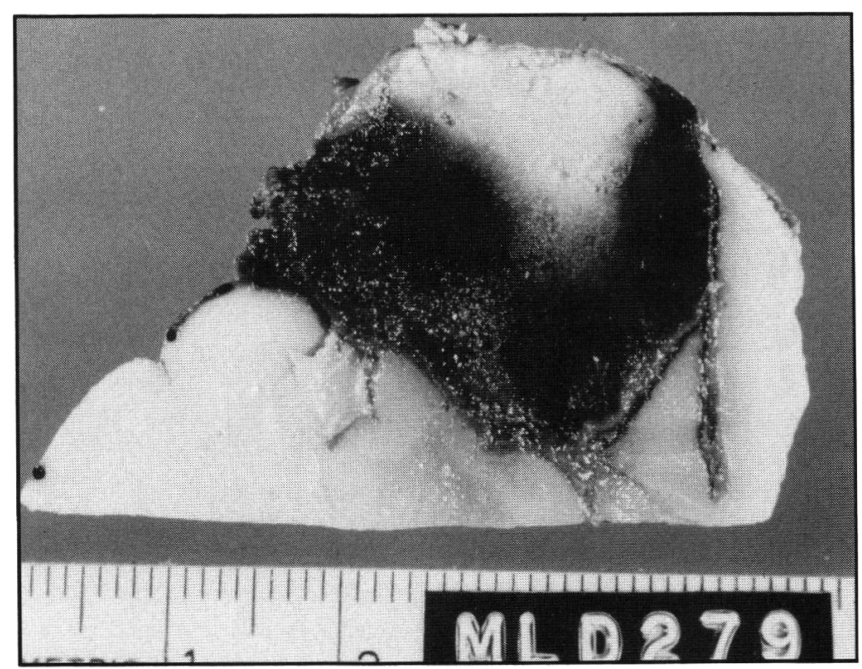

Figure 2 - Case 1 - Crosswsection of meningioma embedded in left frontal pole. Recent hemorrhage into the tumour obscures hemosiderosis from old hemorrhage in the leptomeninges.

of any complications at the surgical site such as sepsis or hemorrhage.

The brain weighed 1,480 grams with generalized gyral flattening. A $2 \mathrm{~cm}$ hemispheric meningioma was found embedded in the left frontal lobe adherent to the overlying dura with associated minimal subdural and subarachnoid hemorrhage (Figures 1-2). There was asymmetric enlargement of the left hemisphere due to marked cerebral edema (Figure 3); bilateral hippocampal uncal and cerebellar tonsillar herniation as well as bilateral hemorrhagic infarction of the posterior cerebral arterial territories were found. Microscopic examination revealed extensive edema in the white matter of the left frontal lobe with diffuse astrocytosis (Figure 4). The remainder of the brainstem showed changes consistent with those of a "non-perfused" brain. The tumour belonged histologically to the category of transitional meningioma with no unusual features (Figure 5). Leptomeninges were fibrotic and contained hemosiderin-laden macrophages indicating previous subarachnoid hemorrhage (Figure 5).

Case 2

This 34 year old woman had a history of migraine headaches going back for several years. A recent neurologic assessment prior to the present admission was considered to be negative.

The patient, at the latest admission, presented to the emergency room for continuing headaches and vomiting. A CT scan of the head showed hyperostosis involving the greater wing of the right sphenoid and the adjacent vault, with a dense soft tissue mass on the inner aspect of the hyperostosis, associated with cerebral edema and shift of the

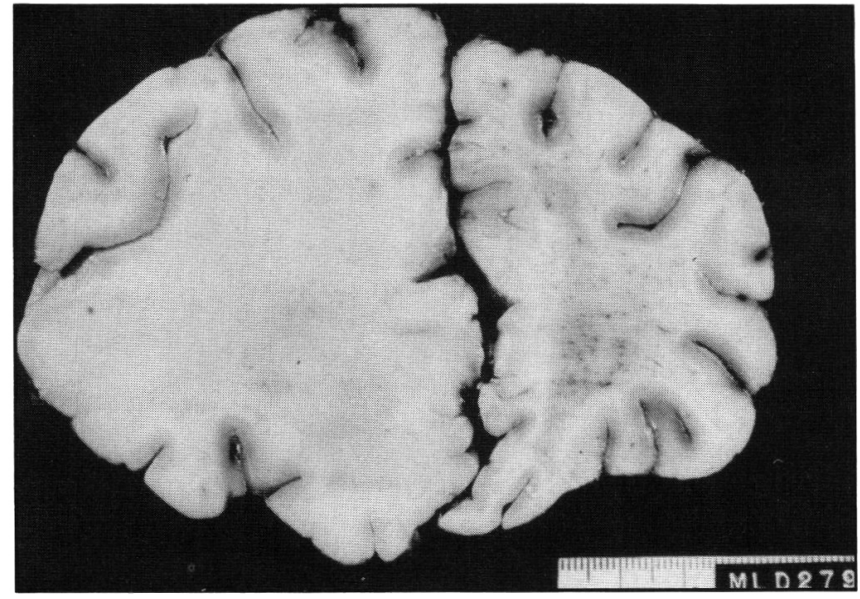

Figure 3 - Case l-Coronal section of frontal lobes showing massive cere. bral edema on the left.

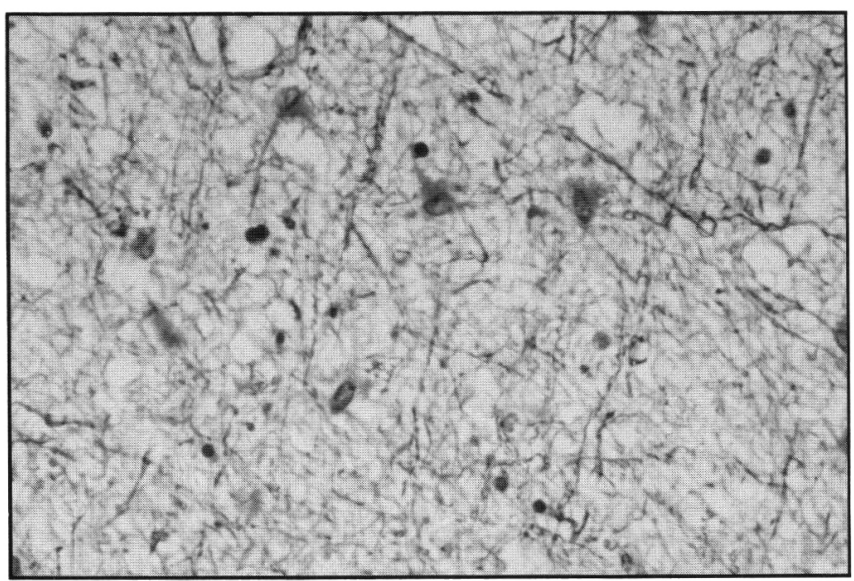

Figure 4 - Case 1 - White matter of the left cerebral hemisphere showing severe diffuse edema and gliosis. LFB-H\&E Obj. $\times 25$

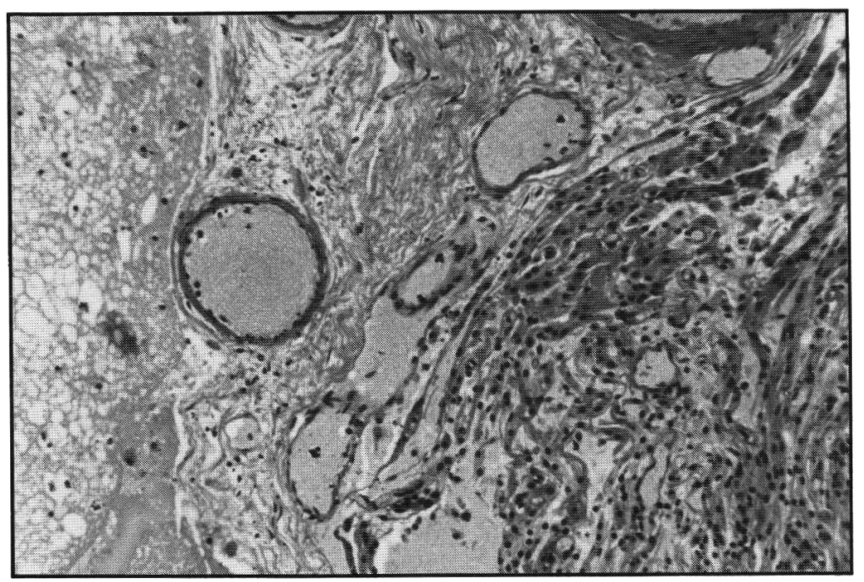

Figure 5 - Case I - Interface between meningioma of transitional type on right and edematous cerebral cortex on left. Intervening leptomeninges arefibrotic and contain hemosiderin-laden macrophages. $H \& E \quad O b j . x I O$.

midline structures to the left. The lesion did not enhance significantly with contrast injection. The clinical diagnosis was of meningioma with marked cerebral edema. The patient's clinical status deteriorated suddenly with a cardiorespiratory arrest. She was maintained on supportive measures that were subsequently discontinued.

A medico-legal autopsy was performed; there was no significant systemic pathology. A meningioma measuring $3 \times 2.5 \mathrm{~cm}$ was found 
firmly attached to the dura over the outer third of the greater wing of the sphenoid bone on the right side with associated bony exostoses. The tumour was embedded in the frontal lobe and there was enlargement of the right hemisphere due to massive cerebral edema (Figure 6), as well as bilateral uncal and cerebellar tonsillar herniation. Necrotic brainstem and cerebellar tissue were seen filling the spinal subarachnoid space as far down as the cauda equina. The tumour histology was that of a meningioma of transitional type, with no evidence of unusual vascularity. The leptomeninges between the tumour and brain tissue showed hemosiderosis indicative of previous hemorrhage and were fibrotic (Figure 7). Reactive astrocytosis and edema of white matter was prominent in much of the right cerebral hemisphere.

\section{Case 3}

This 29 year old woman was admitted to a local hospital with a 2 to 3 week history of severe right frontal headaches associated with nausea, vomiting and pain in the neck. She had suffered from occasional headaches on and off for five years. She was eight months post-partum and had been on oral contraceptives for the past five years. Medical history was otherwise unremarkable. Examination upon admission revealed the patient to be drowsy with pulse $60 / \mathrm{min}$., respiratory rate $18 / \mathrm{min}$., BP $170 / 100 \mathrm{~mm} \mathrm{Hg}$; questionable neck stiffness; fundus normal. CNS examination - negative for any localizing signs.

A lumbar puncture was performed. The opening pressure was $600 \mathrm{mmH}_{2} \mathrm{O}$. The $\mathrm{CSF}$ appeared xanthochromic with 700 red blood cells per $\mathrm{mm}^{3}$. Following the lumbar puncture, the patient developed loss of consciousness with decerebrate posturing. Intravenous mannitol and dexamethasone were administered and the patient was intubated and transferred to The Toronto General Hospital. On arrival, examination revealed no spontaneous respiration with dilated and fixed pupils and absent brainstem reflexes. Supportive measures were subsequently discontinued.

A medico-legal autopsy was performed. Systemic examination of various organ systems were normal. Examination of the skull revealed no evidence of longstanding raised intracranial pressure. A $2.5 \times 2.5 \mathrm{~cm}$ hemispheric tumour was found attached to the dura mater of the right leaf of the tentorium cerebelli. There was evidence of severe edema with gyral flattening bilaterally as well as considerable enlargement of the right hemisphere with shift of the midline structures to the left and herniation of the right cingulate gyrus under the falx. There was rightsided uncal herniation and herniation with necrosis and hemorrhage of the cerebellar tonsils. The tumour in the temporal lobe showed recent intratumoural hemorrhage as well as recent hematoma surrounding the tumour in a cuff and extending into the temporal lobe. The tumour did not permeate the tentorium or associated venous sinuses.

Microscopic examination showed a meningioma of the transitional type with mild cellular pleomorphism and small foci of necrosis (Figure 8). The tumour was not unusual in the degree of vascularity. Areas of recent hemorrhage as well as hemosiderin-laden macrophages indicating old hemorrhage were present in the tumour (Figure 8) and within adjacent fibrotic leptomeninges. The white matter of the entire right cerebral hemisphere showed marked edema and gliosis. Raised intracranial pressure had resulted in recent optic nerve sheat h hemorrhages distending the retrobulbar portion of the optic nerve sheath. Changes of terminal hypoxic encephalopathy were also attributable to raised intracranial pressure.

\section{Discussion}

Cerebral edema in association with meningiomas is unpredictable. As evident from the cases presented and the three cases described by Challa et al, ${ }^{2}$ the swelling may be a greater factor contributing to the morbidity than the direct compression effects of the tumour itself. Such a presentation of meningiomas is uncommon and its incidence remains to be determined. In Case 3, in the present report, there was a five year history of occasional vaguely defined headaches but no definite symptoms relating to the tumour. In Case 1, the tumour was clinically silent until its presentation with malignant cerebral edema. Case 3, had a history of continuing headaches with intact neurologic function until sudden decompensation and

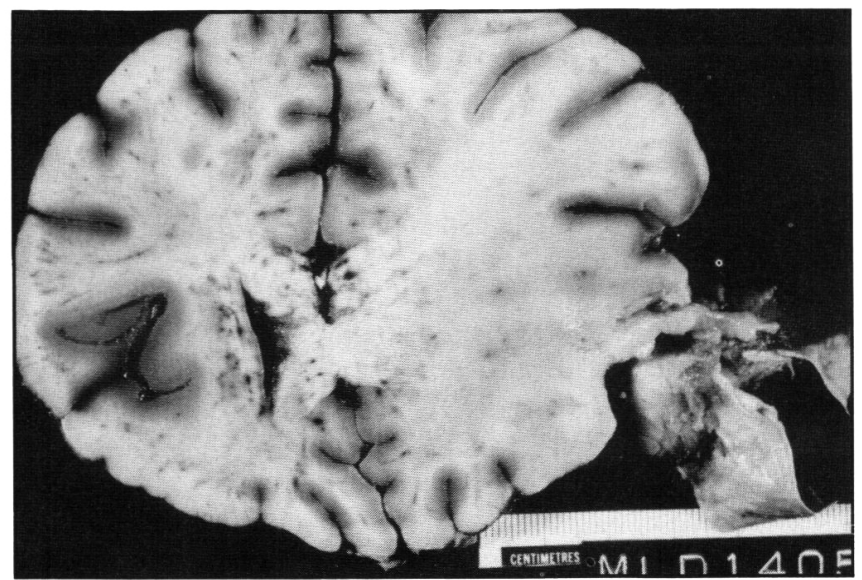

Figure 6 - Case 2 - Coronal section of frontal lobes showing small meningioma with attached dura mater of the sphenoid wing embedded in the temporal lobe. Marked edema of the right cerebral hemisphere is evident.

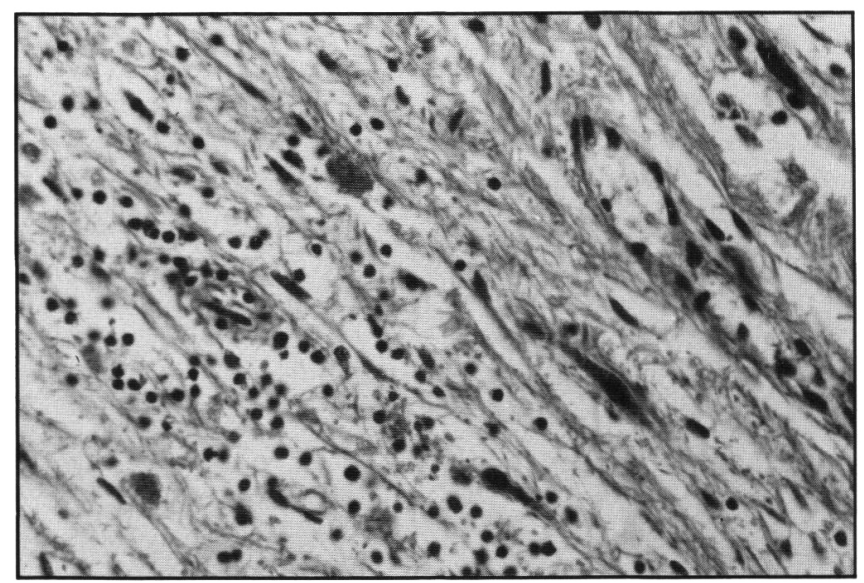

Figure 7 - Case 2 - Fibroticleptomeninges with hemosiderin-laden macrophages from between meningioma and brain. $H \& E$ Obj. $x 25$.

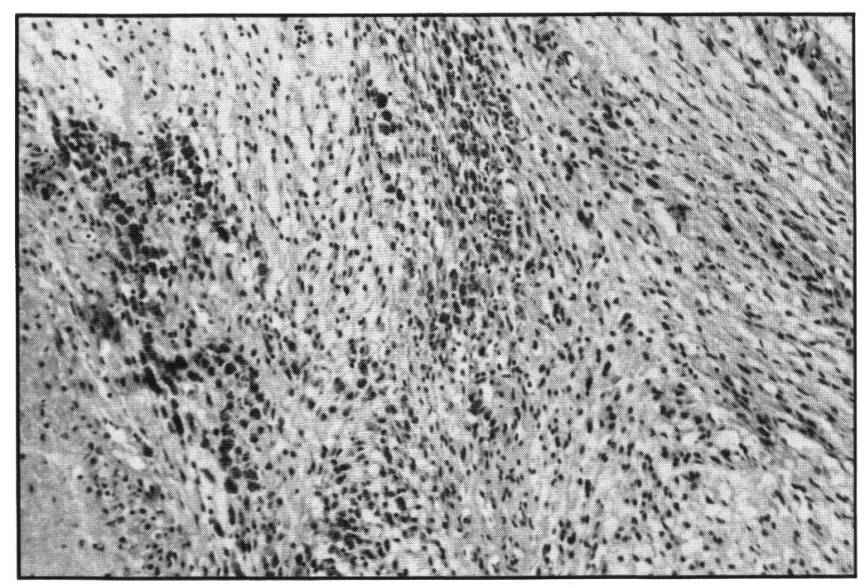

Figure 8-Case 3-Meningioma of transitional type. A necrotic area is seen on the left and near it are prominent hemosiderin-laden macrophages indicative of old spontaneous hemorrhage into the tumour.

acute deterioration. The tumour diameters ranged from 2.5 to $3 \mathrm{~cm}$; in two cases, the tumours arose in the sphenoid ridge and petrous bone, while in one, the tumour was located on the frontal convexity. In Case 3 , the terminal events were no doubt accelerated by the recent intratumoural hemorrhage with paren- 
chymal extension though there was evidence of more chronic cerebral edema of hemispheric white matter.

While such a precipitous presentation of meningioma is distinctly rare, existence of varying degrees of edema with meningiomas is recognized..$^{3-6}$ Smith et $\mathrm{al}^{3}$ in an analysis of 43 cases described 21 cases with edema. Vassilouthis and Ambrose ${ }^{6}$ reported the presence of edema by CT appearances in $92 \%$ of 102 meningiomas. The nature of cerebral edema in meningiomas and its pathogenesis remain poorly understood. Several factors have been examined for possible correlation with the presence of edema with meningiomas. ${ }^{2.7}$ These include the tumour location, size, histologic subtype, cellularity, mitotic activity, vascularity and the presence of secretory-excretory activity.

Fine et $\mathrm{al}^{7}$ commented on a high incidence of edema in sphenoid wing meningiomas and proposed that the proximity in this location to major venous pathways and venous occlusion is a likely explanation. It is apparent from other reports ${ }^{3-6}$ that tumours in other locations without any evidence of venous compression have also been associated with edema. In two of the patients described in the present report, the tumour arose in the petrous bone (Case 3), and the greater wing of the sphenoid (Case 2), but there was no associated venous occlusion. This was also true of Case 1 , where a convexity tumour did not have associated venous compression or occlusion.

Commenting on the tumour size, Gilbert et al ${ }^{4}$ described a positive correlation between tumour size and severity of edema in a series of 55 cases. This is not in keeping with the observations from other series, ${ }^{3}$ where no such linear relationship was apparent. Furthermore, very small tumours may exhibit degrees of cerebral edema out of proportion to tumour size..$^{2,3}$

Smith et $\mathrm{al}^{3}$ suggested an association between edema and tumour cellularity, vascularity, mitotic rate, production of pseudopsammoma bodies and hyaline droplet degeneration. Four tumours in their series with a partial or total hemangiopericytic component were consistently associated with edema. ${ }^{3}$ However, other investigators have shown a predominantly meningothelial component in tumours with marked edema.

Phillipon et al $^{5}$ described prominent secretory-excretory activity ultrastructurally in the tumour cells and raised the possibility that the edema may at least in part, be due to such secretory material. These cells had abundant ergastroplasm with elongated golgi apparatus, numerous vesicles and exocytosis. While secretory-excretory potential of meningiomas is recognized, ${ }^{8.9}$ the exact nature of the secretion is not known. Budka ${ }^{8}$ demonstrated by immunocytochemical techniques strong labelling of the hyaline inclusions in three meningothelial tumours to antisera to human secretory component, $\operatorname{Ig} \mathrm{A}$ and $\operatorname{Ig} \mathrm{M}$.

Phillipon et $\mathrm{al}^{5}$ also analyzed 18 tumours for the presence of steroid hormone receptors but their data have failed to demonstrate a significant difference in meningiomas with and without receptor content in terms of production of cerebral edema.
In our three cases, the meningiomas were of the transitional type with no evidence of high cellularity, cellular atypia or high mitotic rate. There was no evidence of unusual vascularity or a hemangiopericytic (angioblastic) component. A common factor present in all three cases, was evidence of old hemorrhage in the form of hemosiderin-laden phagocytes in the tumour itself and in the adjacent leptomeninges and associated leptomeningeal fibrosis.

The role of even small amounts of spontaneous hemorrhage into meningiomas may well be significant. With most small meningiomas, there is, in effect, a separation between the tumour attached to dura mater and the brain. Any tissue fluid generated within the tumour flows into the subarachnoid space. If hemorrhage occurs in the tumour, the subarachnoid space may be obliterated by fibrosis and fluid from the tumour will thereafter be prevented from escaping freely into the subarachnoid space and instead will enter brain parenchyma with resulting cerebral edema. Larger tumours effectively obliterate the space by their size and are more likely to result in cerebral edema even in the absence of spontaneous hemorrhage into tumour. With small tumours, spontaneous hemorrhage may be the essential factor for the development of massive associated cerebral edema. Massive cerebral edema should be considered in the differential diagnosis of acute neurologic deterioration in patients with meningiomas.

\section{REFERENCES}

1. Russell DS, Rubinstein LJ. Pathology of tumours of the nervous system. Baltimore, Williams and Wilkins Co 1977; ed 4, p 361.

2. Challa VR, Moody DM, Marshall RB, Kelly DL Jr. The vascular component in meningiomas associated with severe cerebral edema Neurosurg 1980; 7: 363-368.

3. Smith HP, Challa VR, Moody DM, Kelly DL Jr. Biological features of meningiomas that determine the production of cerebral edema. Neurosurg 1981; 8: 428-433.

4. Gilbert JJ, Paulseth JE, Coates RK, Malott D. Cerebral edema associated with meningiomas. Neurosurg 1983; 12: 599-605.

5. Phillipon J, Foncin JF, Grog R, Srour A, Poisson M, Pertuiset BF Cerebral edema associated with meningiomas: possible role of a secretory-excretory phenomenon. Neurosurg 1984; 14: 295-301.

6. Vassilouthis J, Ambrose J. Computerized tomography scanning appearances of intracranial meningiomas. J Neurosurg 1979;50: 320-327.

7. Fine $M$, Brazis $P$, Palacios E, Neri G. Computed tomography of sphenoid wing meningiomas: Tumour location related to distal edema. Surg Neurol 1980; 138: 385-390.

8. Budka H. Hyaline inclusions (Pseudopsammoma bodies) in meningiomas: Immunocytochemical demonstration of epithelial-like secretion of secretory component and immunoglobulins $A$ and M. Acta Neuropath 1982; 56: 294-298.

9. Kepes JJ. Meningiomas. Biology, Pathology and Differential Diagnosis. Masson Publishing USA, lnc. New York 1982; Chapter 15, pp 32-33. 